\title{
Properties of Acoustic Emission Signals Coming from Partial Discharges Caused by Modeled Sources Immersed in Transformer Oil
}

\author{
F. Witos ${ }^{a, *}$ AND Z. GACEK ${ }^{b}$ \\ ${ }^{a}$ Department of Optoelectronics, ${ }^{b}$ Institute of Power Systems and Control \\ Silesian University of Technology, Krzywoustego 2, 44-100 Gliwice, Poland
}

\begin{abstract}
Investigation results concerning acoustic emission signals coming from partial discharges generated by modeled sources are presented in the paper. These sources have been made using different bushing ends (without any extra elements and with a thread or a pike) situated directly in the oil, but without screens typical for partial discharge investigations in a bushing. Measurements have been carried out using own measuring acoustic emission system DEMA-COMP and - in a parallel way - computer-aided partial discharges measuring system TE 571 (produced by the firm Haefely Trench). Fundamental and advanced analysis of acoustic emission signals has been made. These signals were recorded in 20 measuring situations which need to multiple installation of acoustic emission sensors. Conclusions resultant from own originate advanced analysis of signals content description of properties revealed by defined acoustic emission descriptors.
\end{abstract}

PACS numbers: 43.40.Le, 52.80.-s, 77.22.Jp, 84.70.+p

\section{Description of modeled sources, a measuring stand and measuring systems}

As a modeled partial discharges (PD) source, made and used during the investigations, was the bushing PTK $123 / 450 / 630$ with additional ends (without any extra elements, with a thread or a pike) situated directly in the oil. This bushing was not equipped with screens typical for PD investigations.

Investigations of $\mathrm{PD}$ generated by modeled sources have been carried out in High Voltage Laboratory of the firm ZTS IZO-ERG in Gliwice and precisely - on the measuring stand presented in Fig. 1. An integral element of this stand is the vat in shape of the cylinder (diameter of $900 \mathrm{~mm}$, height of $1200 \mathrm{~mm}$ ). PD sources have been placed inside the vat filled by the oil. Such PD sources and measuring conditions enable us to observe partial discharges in boundary of the voltage electrode and transformer oil as well as only in the oil.

Acoustic emission (AE) sensors have been placed during investigations at measuring points $P_{\mathrm{A}}, P_{\mathrm{B}}$ and $P_{\mathrm{C}}$ on external surface of the vat within specially prepared clamps. Permanent magnets (elements of sensor clamps) ensured unchangeable position of sensors on vat walls during measurements as well as recurrent thickness of the couple layer (it is the cup grease which ensures good conditions of acoustic contact). Measurements have been carried out using in a parallel way own measuring AE system DEMA-COMP [1-8] and computer-aided PD mea-

\footnotetext{
* corresponding author; e-mail: franciszek.witos@polsl.pl
}

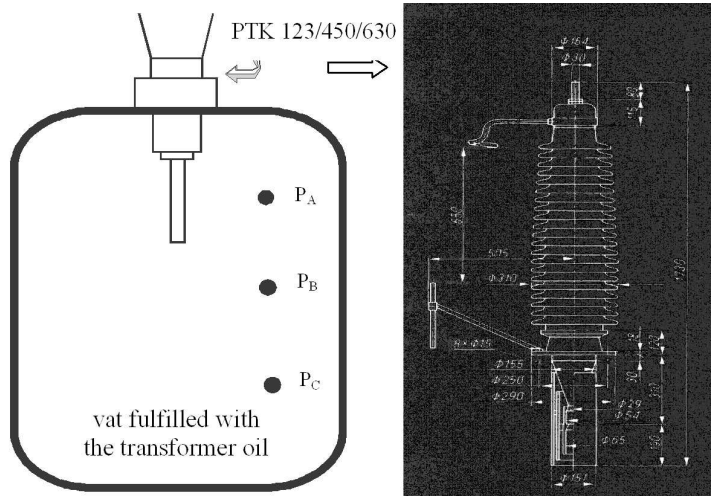

Fig. 1. Scheme of measuring stand used to investigate of PDs generated by modeled sources immersed in the oil fulfilling the vat; $P_{\mathrm{A}}, P_{\mathrm{B}}, P_{\mathrm{C}}$ - measuring points fixed on external surface of the vat.

suring system TE 571, produced by the firm Haefely Trench (investigations of other authors are published in $[9-18])$.

Distances between a modeled source and AE sensors are of several tens of centimeters. These distances are typical for AE signals, generated in many real objects. Owing to that, results of analyses carried out for $\mathrm{AE}$ signals recorded in such a way have also technical value.

Investigations have been made using the following methodology:

1. modeled PD source was introduced into the vat and then maximum of the supply voltage used during the measurements was determined experimentally, 
2. AE sensors were installed at measuring points $P_{\mathrm{A}}$, $P_{\mathrm{B}}, P_{\mathrm{C}}$

3. measurements of PD and apparent charge were carried out for selected supply voltages,

4. every investigation has been repeated for a successive modeled source.

Globally, signals have been recorded in 20 measuring situations. Measuring conditions and input data necessary to analyze are presented in Table I. It should emphasize that recorded measuring data (also in the same measuring path) are obtained in results of montage of $\mathrm{AE}$ sensor which is repeated three times. That causes fluctuations of couple layer dimensions. Therefore, presented analysis of AE signals concerns a complex situation where data are result of repeated installation of $\mathrm{AE}$ sensors.

TABLE I

List of measuring conditions and data for analysis.

\begin{tabular}{c|c|c|c|c}
\hline \hline No. & Source & $\mathrm{U}[\mathrm{kV}]$ & $\mathrm{Q}[\mathrm{pC}]$ & File \\
\hline 1 & bushing & 123 & 1260 & TP11(1) \\
2 & bushing & 140 & 1000 & TP17(1) \\
3 & bushing & 130 & 890 & TP14(1) \\
4 & bushing & 106 & 220 & TP8(1) \\
5 & bushing & 90 & 90 & TP5(1) \\
6 & bushing & 74 & 50 & TP3(1) \\
7 & bushing & 60 & 10 & TP1(1) \\
8 & bushing & 0 & 10 & TSZ1(1) \\
9 & b+point & 106 & 280 & TO16(1) \\
10 & b+point & 90 & 180 & TO12(1) \\
11 & b+point & 74 & 100 & TO7(1) \\
12 & b+point & 50 & 10 & TO1(1) \\
13 & b+point & 0 & 10 & TOS1(1) \\
14 & b+thread & 123 & 500 & TG89(1) \\
15 & b+thread & 106 & 450 & TG85(1) \\
16 & b+thread & 90 & 360 & TG81(1) \\
17 & b+thread & 74 & 220 & TG77(1) \\
18 & b+thread & 60 & 25 & TG73(1) \\
19 & b+thread & 50 & 10 & TG70(1) \\
20 & b+thread & 0 & 10 & TGS3(1) \\
\hline & & & &
\end{tabular}

\section{Fundamental characteristics of AE signals coming from PD generated by modeled sources immersed in transformer oil}

Fundamental characteristics calculated for example AE signals, presented in Figs. 2-5, are as follows:

- phase-time characteristic with minimum, maximum and root mean square (RMS) of the signal, as in Figs. 2-5a (for filtration a band-pass filter of five order was used, filtration band is done as frequency interval at frequency characteristic),

- three-dimensional spectrogram STFT, as in Figs. 2-5b,
- averaging phase characteristic, as in Figs. 2-5c,

- spectral power density as frequency characteristic of a signal with the frequency for main maximum and value of the spectrum for this frequency, as in Figs. 2-5d.
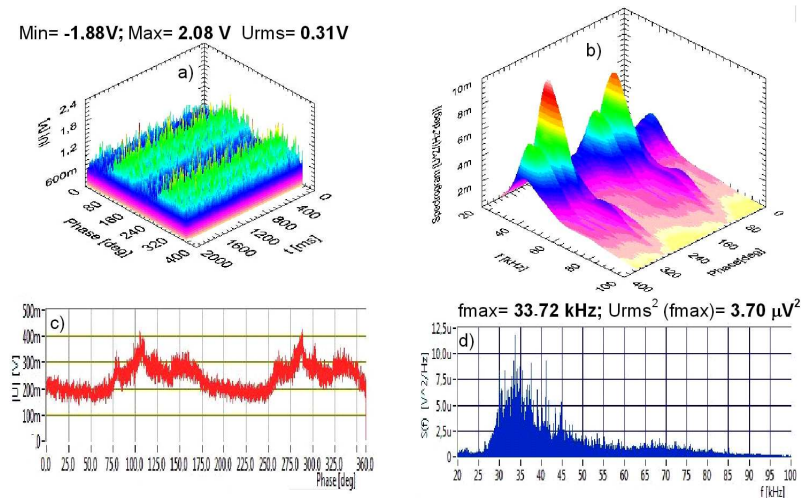

Fig. 2. Fundamental description of the AE signal: (a) phase-time characteristic, (b) averaging STFT spectrogram, (c) averaging phase characteristic, (d) frequency characteristic recorded in measuring conditions: bushing with end without any extra elements, $1000 \mathrm{pC}$, $140 \mathrm{kV}$, measuring line K2 (40 dB, R6\#2), measuring position $P_{\mathrm{B}}$ - TP17(1) file.

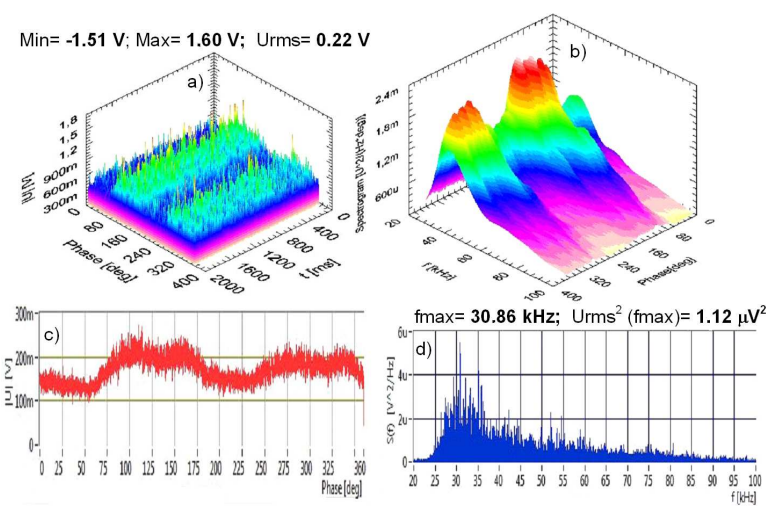

Fig. 3. Fundamental description of the AE signal: (a) phase-time characteristic, (b) averaging STFT spectrogram, (c) averaging phase characteristic, (d) frequency characteristic, recorded in measuring conditions: bushing with end including the thread, $500 \mathrm{pC}, 123 \mathrm{kV}$, measuring line $\mathrm{K} 2$ (40 dB, R6\#2), measuring position $P_{\mathrm{B}}$ - TG69(1) file.

In the consequence of analysis, the whole range of measured apparent charge $Q_{\mathrm{p}}$ (generated by modeled PD sources) has been divided to three intervals: up to $220 \mathrm{pC}$, from $220 \mathrm{pC}$ to $500 \mathrm{pC}$ and below $500 \mathrm{pC}$; such intervals were assigned the symbols A, B and C. Conclusions resultant from analysis of signals are as follows:

- AE signals have simultaneously periodic and random character (Figs. 2-5a), 
TABLE II
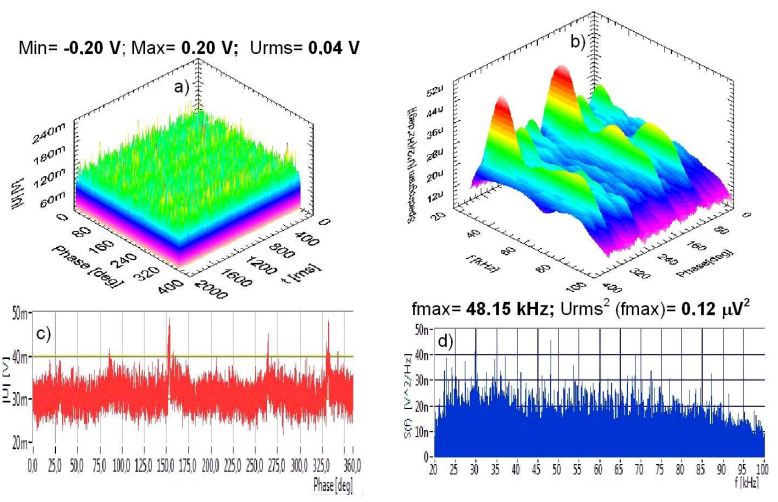

Fig. 4. Fundamental description of the AE signal: (a) phase-time characteristic, (b) averaging STFT spectrogram, (c) averaging phase characteristic, (d) frequency characteristic, recorded in measuring conditions: bushing with end including the thread, $500 \mathrm{pC}, 123 \mathrm{kV}$, measuring line $\mathrm{K} 2$ (40 dB, R6\#2), measuring position $P_{\mathrm{B}}-\mathrm{TO} 7(1)$ file.
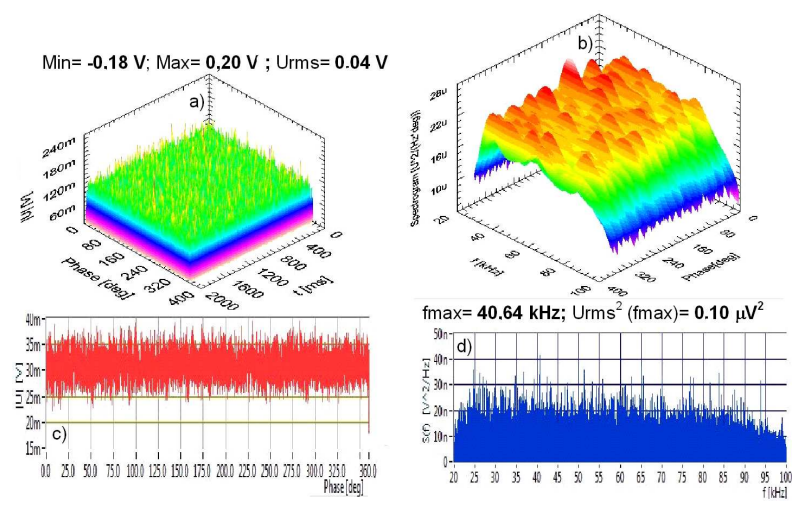

Fig. 5. Fundamental description of the AE signal: (a) phase-time characteristic, (b) averaging STFT spectrogram, (c) averaging phase characteristic, (d) frequency characteristic, recorded in measuring conditions: bushing with end including the thread, $10 \mathrm{pC}, 50 \mathrm{kV}$, measuring line $\mathrm{K} 2$ (40 dB, R6\#2), measuring position $P_{\mathrm{B}}$ - TG70(1) file.

- there are double phase intervals in two halves of supply voltage period at averaging phase-time characteristic (Figs. 2-5c) which correspond to "corridors of high values" in Figs. 2-5a,

- there is a good located main band within AE signals (Figs. 2-5d),

- averaging spectrograms (Figs. 2-5b) show more detailed phase ranges of the main band and additional bands,

- absolute values of quantities at particular characteristics grow when apparent charge introduced by a modeled PD source increases.
Comparison of properties - in time domain — for recorded AE signals generated by noises and PD.

\begin{tabular}{c|l|c|c|c|c}
\hline \hline No. & $\begin{array}{l}\text { Description of } \\
\text { quantity }\end{array}$ & Quantity & Unity & \multicolumn{2}{|c}{ Calculation results } \\
\cline { 2 - 5 } & $\begin{array}{l}\text { Tsz } \\
10 \mathrm{pC}\end{array}$ & $\begin{array}{c}\mathrm{TP} 11 \\
1260 \mathrm{pC}\end{array}$ \\
\hline 2 & $\begin{array}{l}\text { mean value of the } \\
\text { voltage of the sig- } \\
\text { nal }\end{array}$ & $U_{\mathrm{av}}$ & $\mathrm{mV}$ & 18.5 & 12.6 \\
$\begin{array}{l}\text { mean standard } \\
\text { deviation of the } \\
\text { mean value of } \\
\text { the voltage of the } \\
\text { signal }\end{array}$ & $S_{U}$ & $\mathrm{mV}$ & 39.3 & 187.7 \\
\hline 3 & $\begin{array}{l}\text { mean value of the } \\
\text { signal modulus }\end{array}$ & $|U|_{\mathrm{av}}$ & $\mathrm{mV}$ & 15.5 & 150.6 \\
\hline 4 & $\begin{array}{l}\text { coefficient of the } \\
\text { distribution }\end{array}$ & $S_{U} /|U|_{\mathrm{av}}$ & & 2.5 & 1.2 \\
\hline 5 & $\begin{array}{l}\text { maximal value of } \\
\text { the voltage of the } \\
\text { signal }\end{array}$ & $U_{\mathrm{Max}}$ & $\mathrm{mV}$ & 230.2 & 1664.4 \\
\hline 6 & $\begin{array}{l}\text { minimal value of } \\
\text { the voltage of the } \\
\text { signal }\end{array}$ & $U_{\mathrm{Min}}$ & $\mathrm{mV}$ & -203.8 & -2021.2 \\
\hline 7 & $\begin{array}{l}\text { RMS value of the } \\
\text { voltage of the sig- } \\
\text { nal }\end{array}$ & $U_{\mathrm{rms}}$ & $\mathrm{mV}$ & 38.4 & 192.5 \\
\hline
\end{tabular}

Results of quantitative comparison of properties revealed by measuring noises and a signal coming from $\mathrm{PD}$ are presented in Table II. Results of quantitative analysis in domain of signal time are presented in the column "Tsz $10 \mathrm{pC}$ " of Table II. Mean value of signal amplitude is practically equal to zero. Mean value of signal modulus is $15.5 \mathrm{mV}$, whereas mean standard deviation of the mean value is $39.3 \mathrm{mV}$, so it is 2.5 times greater than the mean value. Such a situation shows very "flat" character of Gauss' curve, describing distributions of signal amplitudes - typical for noises of a measuring path. In order to compare results of analysis for signal coming from a modeled PD source, introduced apparent charge of $1260 \mathrm{pC}$, are placed in column "TP11 $1260 \mathrm{pC}$ " of Table II. Mean value of signal modulus is in this case of $150.6 \mathrm{mV}$ (i.e. 10 times higher than for noises), and mean standard deviation of the mean value of the voltage is $187.7 \mathrm{mV}$. These results give already "high" Gauss' distribution for recorded signal amplitudes - typical for information, not for a noise.

\section{Advanced characteristics of AE signals coming from PD generated by modeled sources immersed within transformer oil}

Advanced analysis of AE signals in domain of threshold and frequency has been carried out. Advanced analysis of AE signals in threshold domain includes calculations of 
amplitude distributions and descriptors with acronyms $\mathrm{ADC}, \mathrm{ADP}$ and ADNC, proposed by authors [10-12]. These descriptors describe advancing stage of an AE signal. Obtained results are presented in Table III and in
Fig. 6 (symbol $a$ in Table means descriptor values, symbol $r$ means coefficient of correlation which shows quality of approximation for each descriptors).

TABLE III

Selected quantities describing PD signals in threshold domain.

\begin{tabular}{c|c|c|c|c|c|c|c|c|c|c|c}
\hline \hline & File & $\mathrm{Q}$ & $\mathrm{U}$ & $U_{\mathrm{pp}}$ & $U_{\mathrm{rms}}$ & \multicolumn{2}{|c|}{$\mathrm{ADP}$} & \multicolumn{2}{|c|}{$\mathrm{ADC}$} & \multicolumn{2}{|c}{$\mathrm{ADNC}$} \\
\cline { 6 - 11 } & & {$[\mathrm{pC}]$} & {$[\mathrm{kV}]$} & {$[\mathrm{V}]$} & {$[\mathrm{V}]$} & $a$ & $r$ & $a$ & $r$ & $a$ & $r$ \\
\hline 1 & TP11(1) & 1260 & 123 & 3.84 & 0.19 & -2.3 & 0.99 & -3.3 & 0.99 & -3.6 & 0.99 \\
2 & TP17(1) & 1000 & 140 & 3.96 & 0.31 & -2.3 & 1.00 & -2.7 & 1.00 & -2.8 & 1.00 \\
3 & TP14(1) & 890 & 130 & 4.17 & 0.26 & -2.7 & 1.00 & -3.2 & 1.00 & -3.4 & 1.00 \\
4 & TG89(1) & 500 & 123 & 3.11 & 0.22 & -3.0 & 1.00 & -3.7 & 1.00 & -3.9 & 1.00 \\
5 & TG85(1) & 450 & 106 & 2.79 & 0.15 & -2.7 & 0.99 & -3.7 & 0.97 & -4.2 & 0.99 \\
6 & TG81(1) & 360 & 90 & 2.18 & 0.10 & -3.8 & 0.99 & -5.1 & 0.96 & -5.8 & 0.99 \\
7 & TO16(1) & 280 & 106 & 1.77 & 0.06 & -4.6 & 0.89 & -7.3 & 0.86 & -8.2 & 0.93 \\
8 & TG77(1) & 220 & 74 & 1.75 & 0.06 & -3.3 & 0.94 & -6.0 & 0.93 & -6.3 & 0.94 \\
9 & TP8(1) & 220 & 106 & 0.67 & 0.06 & -16.1 & 0.99 & -17.1 & 0.98 & -17.9 & 0.99 \\
10 & TO12(1) & 180 & 90 & 0.98 & 0.04 & -8.77 & 0.97 & -11.8 & 0.94 & -13.6 & 0.97 \\
11 & TO7(1) & 100 & 74 & 0.42 & 0.04 & -27.1 & 0.99 & -27.5 & 0.98 & -30.6 & 0.99 \\
12 & TP5(1) & 90 & 90 & 0.51 & 0.05 & -21.8 & 0.98 & -24.4 & 0.98 & -24.7 & 0.98 \\
13 & TP3(1) & 50 & 74 & 0.60 & 0.05 & -15.7 & 1.00 & -19.0 & 0.99 & -20.2 & 1.00 \\
14 & TG73(1) & 25 & 60 & 0.49 & 0.04 & -22.8 & 0.97 & -26.4 & 0.98 & -28.0 & 0.98 \\
15 & TP1(1) & 10 & 60 & 0.39 & 0.04 & -33.5 & 0.98 & -31.1 & 0.97 & -35.2 & 0.98 \\
16 & TSZ1(1) & 10 & 0 & 0.52 & 0.04 & -16.8 & 0.99 & -20.3 & 0.99 & -21.9 & 1.00 \\
17 & TO1(1) & 10 & 50 & 2.91 & 0.04 & -26.8 & 1.00 & -28.7 & 0.99 & -31.2 & 1.00 \\
18 & TOS1(1 & 10 & 0 & 0.35 & 0.04 & -30.8 & 0.99 & -30.0 & 0.98 & -33.6 & 0.99 \\
19 & TG70(1) & 10 & 50 & 0.38 & 0.04 & -35.5 & 0.97 & -31.2 & 1.00 & -36.7 & 0.98 \\
20 & TGS3(1) & 10 & 0 & 0.36 & 0.04 & -30.2 & 0.99 & -30.2 & 0.99 & -33.4 & 0.99 \\
& & & & & & & & & &
\end{tabular}

It should be emphasized that signals in Table III are arranged according to apparent charge values introduced by PD source (columns 4). In practice, this means comparison of AE signals recorded during multiple installation of AE sensors for the bushing with different ends.

Tendencies to change of descriptor values depending on apparent charge $Q_{\mathrm{p}}$, introduced by $\mathrm{PD}$ source, are as follows:

- AE descriptor values grow when apparent charge $Q_{\mathrm{p}}$ increases,

- considerable fluctuations of $\mathrm{AE}$ descriptor values within the range of small values of this charge show that - in background of the noises - even single acoustic event can introduce a considerable change in amplitude distribution,

- ADC descriptor among others reveals the most regular distribution of values depending on apparent charge $Q_{\mathrm{p}}$ (introduced by PD source).

Advanced analysis of AE signals in frequency domain includes identification and location of main maxima on frequency characteristics of signals. Identification and location of maxima has been made by "window" method, with approximating of the curves by means of three-parametrical Gauss' curve

$$
y=A \exp \left(-\left(f-f_{0}\right)^{2} /\left(2 \Delta^{2}\right)\right)
$$

with the following parameters: $A$ - amplitude, $f_{0}$ frequency corresponding to a main maximum, $\Delta$ - standard deviation for Gauss' curve. 
TABLE IV

Selected quantities describing PD signals in frequency domain.

\begin{tabular}{|c|c|c|c|c|c|c|c|c|c|c|c|c|}
\hline \multirow[b]{2}{*}{ File } & \multirow[b]{2}{*}{$\begin{array}{c}Q \\
{[\mathrm{pC}]}\end{array}$} & \multirow[b]{2}{*}{$\begin{array}{c}U \\
{[\mathrm{kV}]}\end{array}$} & \multicolumn{5}{|c|}{ K2 } & \multicolumn{5}{|c|}{ K3 } \\
\hline & & & $\begin{array}{c}f_{0} \\
{[\mathrm{kHz}]}\end{array}$ & $\begin{array}{c}\Delta \\
{[\mathrm{kHz}]}\end{array}$ & $\begin{array}{c}A \\
{[U U / \mathrm{Hz}]}\end{array}$ & $\begin{array}{c}f_{\mathrm{d}} \\
{[\mathrm{kHz}]}\end{array}$ & $\begin{array}{c}f_{\mathrm{g}} \\
{[\mathrm{kHz}]}\end{array}$ & $\left.\begin{array}{c}f_{0} \\
{[\mathrm{kHz}]}\end{array}\right]$ & $\begin{array}{c}\Delta \\
{[\mathrm{kHz}]} \\
\end{array}$ & $\begin{array}{c}A \\
{[U U / \mathrm{Hz}]}\end{array}$ & $\begin{array}{c}f_{\mathrm{d}} \\
{[\mathrm{kHz}]}\end{array}$ & $\begin{array}{c}f_{\mathrm{g}} \\
{[\mathrm{kHz}]}\end{array}$ \\
\hline $\mathrm{TP} 11(1)$ & 1260 & 123 & 34.8 & 6.8 & $3.7 \times 10^{-7}$ & 28 & 42 & 33.2 & 7.3 & $3.8 \times 10^{-7}$ & 26 & 41 \\
\hline $\mathrm{TP} 17(1)$ & 1000 & 140 & 35.1 & 6.9 & $8.8 \times 10^{-7}$ & 28 & 42 & 33.2 & 7.6 & $8.6 \times 10^{-7}$ & 26 & 41 \\
\hline $\mathrm{TP} 14(1)$ & 890 & 130 & 35.1 & 7.0 & $6.5 \times 10^{-7}$ & 28 & 42 & 33.3 & 7.6 & $6.5 \times 10^{-7}$ & 26 & 41 \\
\hline TG89(1) & 500 & 123 & 33.0 & 9.0 & $2.7 \times 10^{-7}$ & 24 & 42 & 31.6 & 7.9 & $3.0 \times 10^{-6}$ & 24 & 39 \\
\hline TG85(1) & 450 & 106 & 33.0 & 8.4 & $1.5 \times 10^{-7}$ & 25 & 41 & 31.4 & 8.4 & $2.0 \times 10^{-7}$ & 23 & 40 \\
\hline TG81(1) & 360 & 90 & 33.0 & 8.5 & $6.5 \times 10^{-8}$ & 24 & 41 & 31.7 & 8.4 & $7.0 \times 10^{-8}$ & 23 & 40 \\
\hline TO16(1) & 280 & 106 & 33.0 & 6.7 & $3.2 \times 10^{-8}$ & 26 & 40 & 29.4 & 5.6 & $2.0 \times 10^{-8}$ & 24 & 35 \\
\hline $\mathrm{TP} 8(1)$ & 220 & 106 & 33.7 & 7.4 & $2.9 \times 10^{-8}$ & 26 & 41 & 32.0 & 8.0 & $3.7 \times 10^{-8}$ & 24 & 40 \\
\hline TG77(1) & 220 & 74 & 32.9 & 10.0 & $1.8 \times 10^{-8}$ & 23 & 43 & 31.8 & 11.0 & $2.3 \times 10^{-8}$ & 21 & 43 \\
\hline TO12(1) & 180 & 90 & 32.3 & 8.1 & $8.8 \times 10^{-9}$ & 24 & 40 & 28.9 & 7.1 & $8.2 \times 10^{-9}$ & 22 & 36 \\
\hline TO7(1) & 100 & 74 & none & & & & & none & & & & \\
\hline $\operatorname{TP5}(1)$ & 90 & 90 & 33.2 & 8.0 & $1.5 \times 10^{-8}$ & 25 & 41 & 31.8 & 9.3 & $2.1 \times 10^{-8}$ & 22 & 41 \\
\hline TP3(1) & 50 & 74 & none & & & & & none & & & & \\
\hline TG73(1) & 25 & 60 & none & & & & & none & & & & \\
\hline $\mathrm{TP} 1(2)$ & 10 & 60 & none & & & & & none & & & & \\
\hline TO1(1) & 10 & 50 & none & & & & & none & & & & \\
\hline TG70(1) & 10 & 50 & none & & & & & none & & & & \\
\hline TSZ1 & 0 & 0 & none & & & & & none & & & & \\
\hline TOS1(1) & 0 & 0 & none & & & & & none & & & & \\
\hline TGS3(1) & 0 & 0 & none & & & & & none & & & & \\
\hline
\end{tabular}

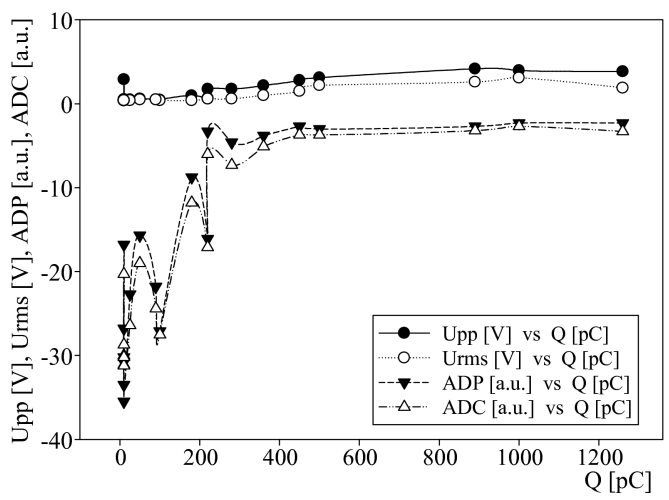

Fig. 6. Quantities describing AE signals registered in measuring channels K2 for different PD sources: bushing with the end without additional elements, bushing with sharp and bushing with thread.

Results of frequency analysis in Table IV show that frequency characteristics of PD signals obtained by means of $\mathrm{AE}$ method have the following properties:

- there is a lower limit of sensitivity on the level up to $100 \mathrm{pC}$,

- there is no visible dependence of main band posi- tion on apparent charge value included by modeled source; signals belong to bands $23-43 \mathrm{kHz}$ (measuring path $\mathrm{K} 2$ ) and $21-43 \mathrm{kHz}$ (measuring path K3),

- signals recorded by AE sensor situated at larger distance from a modeled source have frequency band moved in direction of lower frequencies (in comparison with signals recorded by $\mathrm{AE}$ sensor situated at nearer distance from a modeled source) which results from comparison of parameters of signals recorded in two measuring paths.

\section{Recapitulation}

As a modeled PD source was the bushing with different additional ends (without any extra elements or with a thread and a pike) situated directly in the oil (without screens typical for investigations of PD in a bushing). Modeled PD sources enable us to observe partial discharges in boundary of the voltage electrode and also in the transformer oil.

Measurements have been carried out using - in a parallel way — own measuring AE system DEMA-COMP and computer-aided PD measuring system type TE 571, produced by the firm Haefely Trench. Globally, signals 
have been recorded in 20 measuring situations which need montage of AE sensors many times.

Fundamental and advanced analysis of recorded $\mathrm{AE}$ signals has been carried out.

Fundamental analysis leads to the following conclusions:

- AE signals have simultaneously periodic and random character,

- there are double phase intervals in two halves of supply voltage period which correspond to "corridors of high values" on phase-time characteristics,

- there is good located main band in AE signals,

- averaging spectrograms show more detailed phase ranges of the main band and additional bands,

- absolute values of quantities on particular characteristics grow when apparent charge introduced by a modeled PD source increases.

Advanced analysis of recorded signals give the following results:

- there is a visible dependence of main band position on the value of apparent charge introduced by a modeled source,

- comparison of parameters of signals recorded in two measuring paths shows that signals recorded by EA sensor situated at larger distance from a modeled source have frequency band moved in direction of lower frequencies,

- AE descriptors, allocated to AE signals the so-called advancing stage, arrange the signals and within a framework of analyzed group of AE signals - it is arrangement similar to arrangement according to apparent charge $Q$; fluctuations are caused by additional phenomena which subjected $\mathrm{AE}$ waves during their propagation.

\section{References}

[1] F. Witos, Z. Gacek, in: CIGRE 39th Int. Session, Paris 2002, p. 11

[2] F. Witos, Z. Gacek, A. Opilski, Arch. Acoust. 27, 65 (2002).
[3] F. Witos, Z. Gacek, in: Proc. XIIIth Int. Symp. on High Voltage Engineering, Netherlands 2003, Ed. Smit, Milpress, Rotterdam 2003.

[4] F. Witos, Z. Gacek, P. Paduch, Mol. Quant. Acoust. 28, 271 (2007).

[5] F. Witos, Investigation of partial discharges by means of acoustic emission method and electric method, Wyd. Politechniki Śląskiej, Gliwice 2008 (in Polish).

[6] F. Witos, Z. Gacek, Europ. Phys. J.-Spec. Top. 154, 239 (2008).

[7] F. Witos, Z. Gacek, Z. Opilski, Acta Phys. Pol. A 114, A-249 (2008)

[8] T. Boczar, IEEE Trans. Dielectric Electrical Insulation, 8, 598 (2001).

[9] T. Boczar, M. Szmechta, D. Zmarzły, Mol. Quant. Acoust. 28, 39 (2007)

[10] T. Boczar, S. Borucki, A. Cichon, Mol. Quant. Acoust. 28, 13 (2007)

[11] T. Boczar, S. Borucki, A. Cichon, M. Lorenc, Acta Phys. Pol. A 114, A-21 (2008).

[12] Z. Deheng, T. Kexiong, J. Xianche, in: II Conf. Properties and Application of Dielectric Materials, vol. 2, Pekin 1988, p. 614

[13] J. Deng,H.Xiao, W.Huo, M.Luo, R.May, A.Wang, Y.Liu, Opt. Laser Technol. 33, 305 (2001).

[14] A.S. Faraq, M.H. Shewdi, X.Jin, C.Wang, T.C.Cheng, X.Dong, S.Gao, W.Jing, Z.Wang, Electric Power System Research 50, 47 (1999).

[15] L.E. Lundgaard, IEEE EI Magazine 8, 34 (1992).

[16] M. MacAlpine, Z. Zhiquiang, M.S. Demokan, Electric Power System Research 63, 27 (2002).

[17] J. Skubis, Acoustic emission within investigation of dielectric insulation of electroenergetic installations, IPPT PAN, Warszawa 1993 (in Polish).

[18] A. Sliwinski, Ultrasounds and their applications, WNT, Warszawa 2001 (in Polish).

[19] A. Szpakowski, C. Tyszkiewicz, T. Pustelny, Acta Phys. Pol. A 114, A-237 (2008). 